\title{
Response of Coated Laminated Glass Panels Subjected to Combined Blast and Temperature Loadings
}

\author{
Emad A. Makki ${ }^{1,2} \cdot$ Prathmesh Naik Parrikar $^{1} \cdot$ Arun Shukla $^{1}$
}

Received: 26 August 2015/ Accepted: 26 October 2015/Published online: 30 October 2015

(C) Society for Experimental Mechanics, Inc 2015

\begin{abstract}
An experimental study was conducted to investigate the performance of coated laminated safety glass panels under extreme temperatures and blast loading. Using a shock tube apparatus, specimens were evaluated under room temperature $\left(25^{\circ} \mathrm{C}\right)$, low temperatures $(-10$ and $\left.0{ }^{\circ} \mathrm{C}\right)$, and high temperatures $\left(50,80,110{ }^{\circ} \mathrm{C}\right)$. Special environmental chambers were designed to heat up and cool down the panels to the required temperatures prior to blast loading. To mimic real applications for glass windows, specimens were clamped fully along the boundaries during experimentation. For each experiment, the incident and reflected shock wave pressure profiles were recorded using pressure transducers located on the muzzle of the shock tube. The real-time deformation of the sandwich specimens was recorded using two high-speed cameras. Three-dimensional digital image correlation was used to analyze the high-speed images and compute the full-field deformation, in-plane strains, and velocities during the blast-loading event. A post-mortem study of the sandwich specimen was performed to investigate the effectiveness of such materials under different temperatures to withstand these shock loads. Experiments were conducted to characterize the tensile behavior of the coating material as a function of temperature. The mechanisms of failure of the panel are in agreement with the failure mechanisms outlined for
\end{abstract}

Emad A. Makki

emakki@my.uri.edu; eamakki@uqu.edu.sa

1 Dynamic Photo Mechanics Laboratory, Department of Mechanical, Industrial and Systems Engineering, University of Rhode Island, Kingston, RI 02881, USA

2 Department of Mechanical Engineering, College of Engineering and Islamic Architecture, Umm Al-Qura University, Makkah, Saudi Arabia laminated safety glass (LSG) in previous studies. The results indicated that polymeric thin sheet coating on both outer faces of the LSG panel had major influence on mitigating the blast loading and containing the glass fragments. The composite panel showed great endurance during the blast loading for temperatures from 0 to $80{ }^{\circ} \mathrm{C}$. The failure of panel at $-10{ }^{\circ} \mathrm{C}$ is attributed to the glass transition of the coating material and the failure at $110{ }^{\circ} \mathrm{C}$ is likely due tearing of the coating by the glass fragments.

Keywords Shock wave loading - Environment temperature - Sandwich glass composite - Digital image correlation $\cdot$ High speed photography $\cdot$ Blast mitigation

\section{Introduction}

Most post-investigations of incidents involving explosions have cited that the majority of human casualties were not caused by the air blast wave or bomb fragments themselves. Rather, it was fragments of objects coming from glass windows, walls, and other unsecured bodies that were responsible for the majority of human injury [1-3]. Monolithic glass panes, necessary as they are, are often the culprit in these sorts of injuries due to the fact that they offer little resistance to air blast loads. Thus, the development of blast-resistant windows has been a topic of interest among many researchers all over the world.

There are many different types of blast-resistant panels, including clear, wired, tempered, and laminated safety glass (LSG) panels [4]. In comparison to most of the commercial glass panels, LSG panels have been proven to have better blast and impact resistance and hence have been the central focus of research on blast resistant windows [5-7]. Typical LSG panel consists of two glass plates 
bounded together by a polyvinyl butyral (PVB) polymer interlayer. This interlayer holds the glass splinters and continues to deform significantly after the glass fractures, in which case, the composite structure exhibits large deformations and dissipates the blast energy. In accordance with popular blast-proof window designs specified by the Department of Defense UFC standard [8] and the ASTM standard [9], $3 \mathrm{~mm}$ thick glass panes are used in the LSG panel. It was proven by Wei et al. that the most effective PVB thickness for blast mitigation is any number between 0.76 and $1.52 \mathrm{~mm}$ [10], resulting in a configuration with minimal thickness of $6.76 \mathrm{~mm}$ for the LSG panel.

Experimental studies have been conducted to understand the response of laminated glass panes and its performance under blast loading. Larcher et al. [11] described the general behavior and failure modes of LSG under blast loading. Initially, glass panes deform elastically and absorb some of the blast energy where the outer glass ply cracks and the inner one breaks. The PVB interlayer deforms elastically and then plastically. The failure of the interlayer occurs at ultimate strain or is cut by the glass fragments. Hooper et al. [12, 13] performed open-air blast experiments to provide full field deflection measurements at all points across the LSG pane using high-speed 3D digital image correlation (DIC) along with load measurements at the joints. They reported that the strain is concentrated near the edges and corners leading to tearing of the PVB around the edges. Wei et al. [14] studied the significant influence of the negative phase of the blast loading on the dynamic response of the glazing panel. They concluded that the mid-span deflection and stress caused by the negative phase could be as much as twice those caused by the positive phase. Zhang et al. [15] studied the boundary effects on the performance of LSG windows. They found that the sliding boundary, which allows longitudinal and inplane movement of the panel, can effectively reduce the LSG response against the blast loading and also reduce the joint failure possibility as compared to fully fixed boundary.

Numerical studies of firmly clamped LSG panels by Zhang et al. [16] show three failure modes. Shear failure occurs on the interlayer along the boundary when it is subjected to impulsive load with significant reflected pressure in short duration; flexural bending failure is expected when it is under relatively long duration loading; and a combined shear and flexural failure will be formed on the PVB interlayer if it is under intermediate dynamic loading. H.D. Hidallana-Gamage et al. [17] performed an analytical procedure using the maximum principle stress as the failure criterion for glass and the von mises stress as the failure criterion for interlayer and sealant materials to predict failure of LSG panel under blast loading. They reported that the glass panes absorb most of the blast energy. As a percentage of total energy absorption, glass panes showed $80 \%$ energy absorption, PVB interlayer had energy absorption of $12 \%$, and the sealant joints showed $8 \%$ energy absorption most of the time. The authors concluded that LSG panels should be designed to fail by tearing of the interlayer rather than failure at the supports to achieve a desired level of protection. Many researchers have studied the dynamic properties of glass $[18,19]$ and PVB materials $[20,21]$ to help design better glass resistant panels.

A recent investigation by P. Kumar and Shukla reported that a sandwich configuration consisting of a PVB interlayer, two glass panels, with outer protective films was the most effective at mitigating blast-loadings compared to other glass systems, such as tempered glass, wired glass, and LSG [5]. This promising sandwich structure needs more research to investigate its bounds of its utility. Thus, in this study we aim to evaluate the blast performance of this sandwich structure in a variety of temperature environments. A shock tube facility generated the dynamic shock loading imparted to the glass composites while a series of pressure sensors and high-speed cameras were used to obtain pressure profiles and images of the specimen during loading at the different temperatures. Three-dimensional Digital Image Correlation (3D DIC) was used to analyze the high-speed images and compute the full-field deformation, in-plane strains, and velocities during the blast-loading event. The composite panel showed superior blast mitigating property for temperatures ranging from 0 to $80{ }^{\circ} \mathrm{C}$. The polymeric thin sheet coating and PVB both contribute in containment of the glass fragments and withstand the blast load. The failure of the sandwich panel at $-10{ }^{\circ} \mathrm{C}$ is attributed to the glass transition of coating material and the failure at $110{ }^{\circ} \mathrm{C}$ is likely due tearing of the coating by the glass fragments.

\section{Experimental Procedures}

In the present study, the performance and dynamic behavior of sandwich specimen under shock loading was evaluated. To verify consistency and repeatability in the experimental results, at least three blast-loading experiments were performed at each temperature environment. Experiments were carried out at temperatures of $-10,0$, $25,50,80$ and $110{ }^{\circ} \mathrm{C}$.

\section{Sandwich Specimen Geometry and Materials}

The sandwich specimens used for shock loading experiments were prepared by adhering a protective film (provided by XO ARMOR ${ }^{\circledR}$ with a thickness of $0.279 \mathrm{~mm}$ ) on both of the outer faces of the LSG panel using a special 
chemical adhesive $\mathrm{XO}^{\circledR}$ bond. Figure 1a shows a detailed schematic for the sandwich specimen configuration. The LSG panel used in this study consists of two clear glass plates (each ply had thickness of $3.14 \mathrm{~mm}$ ) made out of Soda-Lime-Silica Glass which were bonded with $0.76 \mathrm{~mm}$-thick transparent PVB interlayer as shown in Fig. 1a, b. The overall dimensions for the sandwich specimens were $305 \mathrm{~mm}$ long, $305 \mathrm{~mm}$ wide and $7.6 \mathrm{~mm}$ thick. According to the LSG manufacturers, the PVB interlayer was first cut to the correct size and sandwiched between two clear glass plates. The sandwiched glass assembly was then passed along the production line where it moved through an oven while the air was being pressed out. After that, it was heated and pressurized in a computer-controlled autoclave for $24 \mathrm{~h}$. This treatment process yields good bonding strength and gives the glass plies clear optical properties. The $\mathrm{XO}^{\circledR}$ bond penetrates the glass and forms a permanent, nano-level molecular bond between the glass and the $\mathrm{XO}^{\circledR}$ film.

\section{Blast Loading Under Different Temperatures}

The experiments were conducted using the shock tube apparatus, which can produce transient blast loading. The shock tube facility at the University of Rhode Island, shown in Fig. 2, had already been developed and has the capability to generate a controllable shock wave loading on the target specimen up to a $2.2 \mathrm{MPa}$ overpressure $[22,23]$. In the present study, the shock tube had an overall length of $8 \mathrm{~m}$. It consists of three main sections: high pressurized (driver) section, low pressure (driven) section, and muzzle section. Both driver and driven sections had diameter of $0.15 \mathrm{~m}$ and they were separated by a diaphragm. The

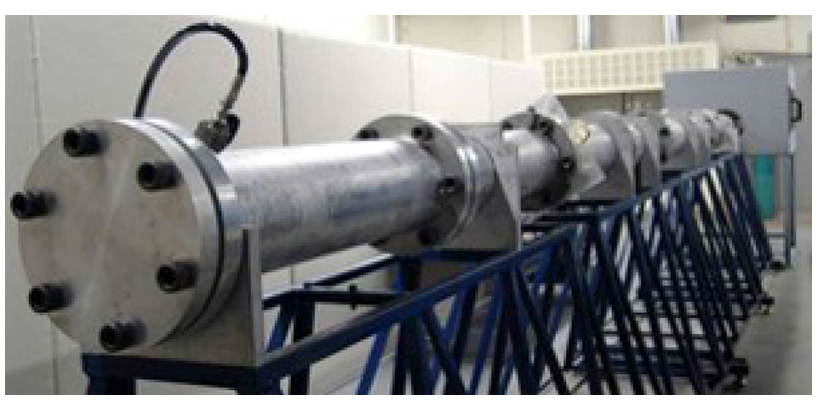

Fig. 2 Shock tube facility

muzzle end was the final section of the shock tube facility and had diameter of $0.07 \mathrm{~m}$. During the experiments, the driver section was pressurized with compressed Helium gas, creating a pressure difference across the diaphragm that is composed of a variable number of Mylar sheets. Thus the pressure needed to rupture the diaphragm is controlled by the quantity and thickness of the Mylar sheets. When the pressure reaches its critical value as determined by the Mylar, the diaphragm ruptures, forming a supersonic shock wave that travels towards the target specimen. The theoretical assumptions which were used to describe the gas flow in the shock tube and the detailed compressible gas flow equations have been previously established in the literature [24, 25].

In order to investigate the actual loading conditions in windows, sandwich specimens were held under fully clamped boundary conditions during blast loading. A detailed fixture support design is shown in Fig. 3a. The inner dimensions of the clamping fixture (window frame) were $267 \times 267 \mathrm{~mm}$. Rubber supports were placed between the steel metal clamping supports and the
Fig. 1 Detailed schematic of sandwich specimen

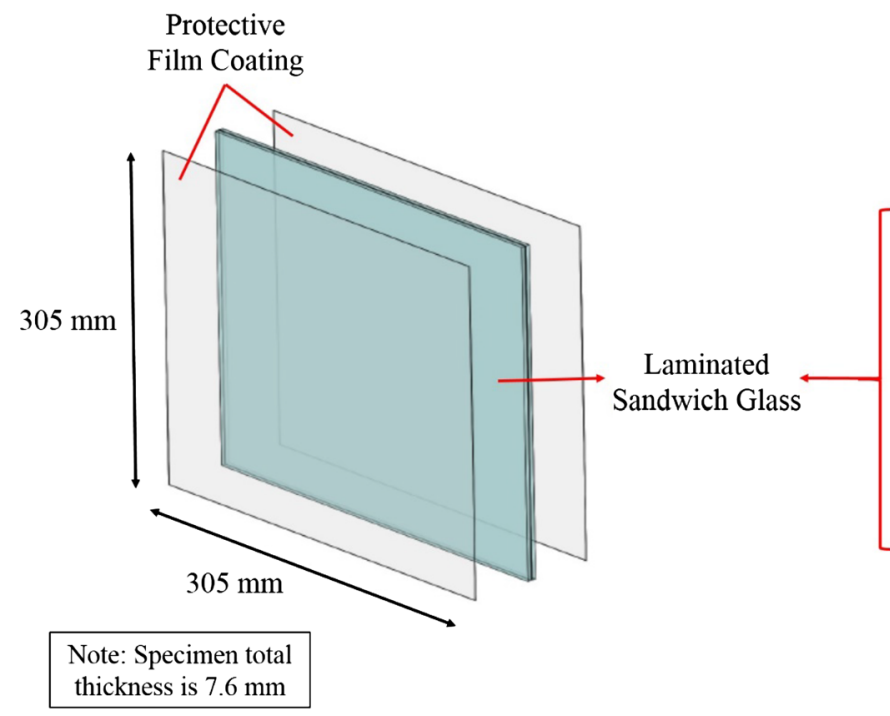

(a) Specimen configuration
Protective Film Coating

Soda-Lime-Silica Glass

Polyvinyl Butyral (PVB)

Soda-Lime-Silica Glass

Protective Film Coating

(b) Specimen layers 


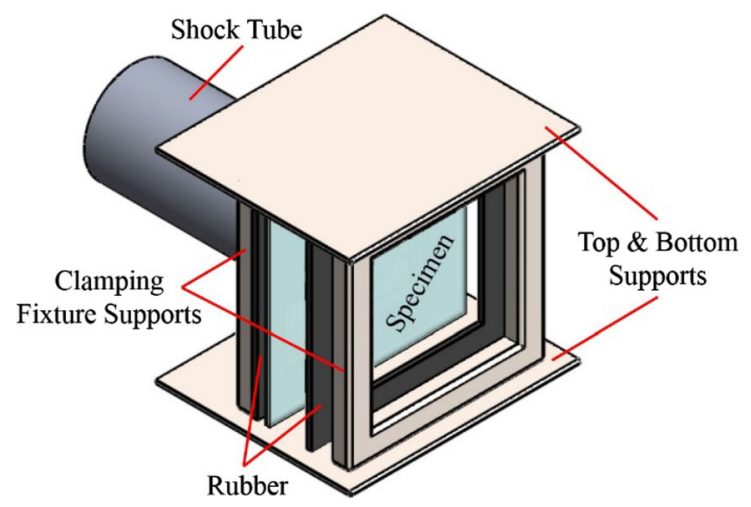

(a) Fully clamped boundary conditions fixture

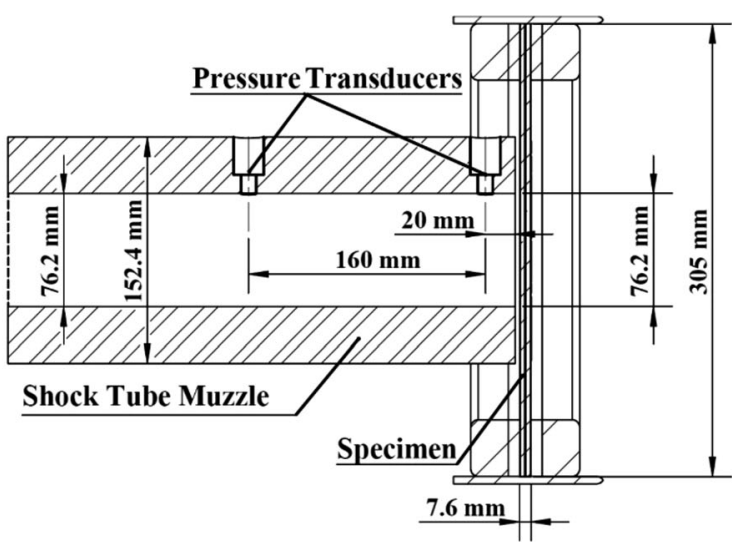

(b) Detailed dimensions of the muzzle and specimen loading area

Fig. 3 Schematics of the muzzle of the shock tube and fixture

sandwich specimen to avoid breaking any glass during the clamping process. The sandwich specimen was placed in the robust supports and positioned $0.1 \mathrm{~mm}$ away from the end of the muzzle section. The shock tube end muzzle was aligned so that its axis coincided with the center of the front face of the sandwich specimen. The blast loading was applied over a central circular area $76.2 \mathrm{~mm}$ in diameter. The pressure pulses were recorded by two pressure transducers (PCB CA102B) mounted at the muzzle exit, located with respect to the front face of the specimen as shown in Fig. 3b. These pressure sensors were kept separated by a distance of $160.0 \mathrm{~mm}$ and the closest pressure transducer to the specimen was located $20.0 \mathrm{~mm}$ away from the muzzle end. These sensors were installed in such a way as to keep the front face of the sensor flush to the inner wall surface of the muzzle section. The incident and reflected shock wave velocities in the tube were obtained by using the distance between the transducers and the shock wave travel time.
The pressure applied on the sandwich specimen was recorded by the sensor closest to the sandwich specimen. A digital oscilloscope (TDS3014C) was used to record the pressure history during each dynamic event at 1.0 MegaSamples/s. A diaphragm configuration of 2 stacked plies of Mylar sheets (total thickness of $0.356 \mathrm{~mm}$ ) was used to generate the shock loading. The incident and reflected peak pressures were all the same for different temperature environments. This observation agrees with previous work [26] which indicates that the reflected peak pressure for different materials only relies on the incident peak pressure. A typical pressure loading history is shown in Fig. 4a. The incoming shock waves had an average incident peak pressure of $0.6 \mathrm{MPa}$ and reflected peak pressures of $2.5 \mathrm{MPa}$. According to the sensor's readings, the peak overpressure value of the incident pressure profile was six times the value of ambient air. The reflected pressure showed the loading value experienced at the front
Fig. 4 Typical pressure pulses and the true impinging impulse on specimen

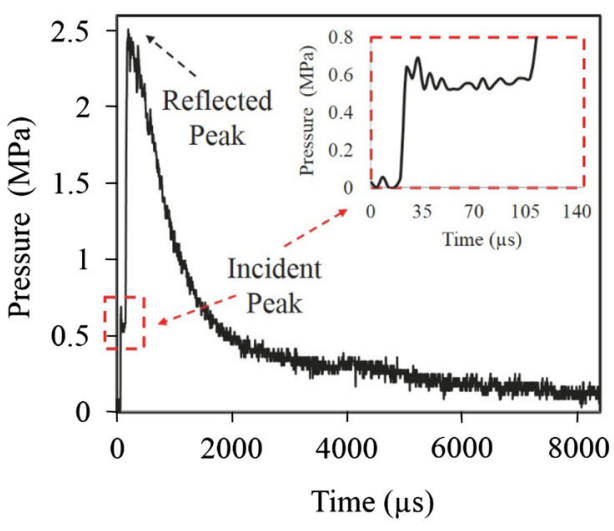

(a) Incident and reflected pressure profiles

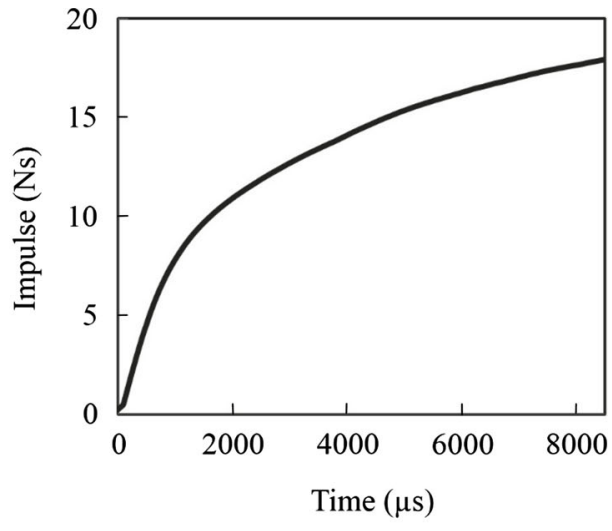

(b) True duration of imparted impulse on specimen 
face of the specimen. The generated shock wave had a short rise time of about $80 \mu$ s and showed an exponential decay period of approximately $2000 \mu \mathrm{s}$. The shock wave traveled out of the muzzle with an average velocity of $800 \mathrm{~m} / \mathrm{s}$ and was reflected with an average velocity of $350 \mathrm{~m} / \mathrm{s}$. In this case, the blast shock had an approximate Mach number of 2.40. Figure $4 \mathrm{~b}$ shows the typical impulse imparted to the specimen. This was obtained by integrating the force-time data of the reflected pressure history. The sandwich specimen at different temperatures obtained a maximum impulse of $18 \mathrm{Ns}$ from the shock loading.

For testing the sandwich specimen under high temperatures, a heating element was used to heat the internal environment of a thermally insulated chamber (shown in Fig. 5a). By supplying different voltages $(0-100 \mathrm{~V})$ to the chamber, various steady-state temperature values were achieved. Lab-View software was used for recording and plotting the temperature-time calibration curves by using a thermocouple adaptor which converts the voltage signals measured to temperature. To perform high temperature experiments, the sandwich specimens were heated for approximately $200 \mathrm{~min}$ until the desired temperature was reached. The temperature inside the chamber was maintained at the designed level for at least $15 \mathrm{~min}$ before the blast experiment. A typical $80{ }^{\circ} \mathrm{C}$ calibrated temperaturetime plot is shown in Fig. 5b. For low temperature testing, the sandwich specimen was cooled down in a freezer for about an hour up to a minimum temperature of $\left(-20^{\circ} \mathrm{C}\right)$. The sandwich specimens were sealed from the freezer's environment so no humidity was accumulated during the cooling process. Once desired temperature was achieved, the sandwich specimen was placed in the support fixture (inside the shock-tube facility) and tested after a certain calibrated waiting time. It is important to note that the sandwich specimen will begin to warm up after it is removed from the freezer, and thus a series of calibration tests were conducted to ascertain how long the specimen would take to reach the temperatures desired for testing $\left(-10,0{ }^{\circ} \mathrm{C}\right)$. In order to perform blast loading experiments at -10 and $0{ }^{\circ} \mathrm{C}$, the sandwich specimen was held in room temperature for approximately 2 and $5 \mathrm{~min}$, respectively as shown in Fig. 6.

A high-speed photography system was used to record the loading event at 20,000 fps with an image resolution of $512 \times 512$ pixels for one second time duration. The inter frame time between the recorded images was 50 microseconds. This photography system consists of two [Photron SA1] high-speed digital cameras, which were located behind the sandwich specimen (the detailed experimental set-up is shown in Fig. 7). The resolution of these cameras was selected to correspond with the exposed blast area $(152.4 \times 152.4 \mathrm{~mm})$ of the sandwich specimen. Two high intensity light sources were used to illuminate the sandwich specimens due to the short exposure times during the experiments. The high-speed photography system first was calibrated to ensure accurate measured results throughout the blast loading event. This was done by using the calibration grid plate and procedures provided by Correlated Solutions. A non-contact 3-D Digital Image Correlation

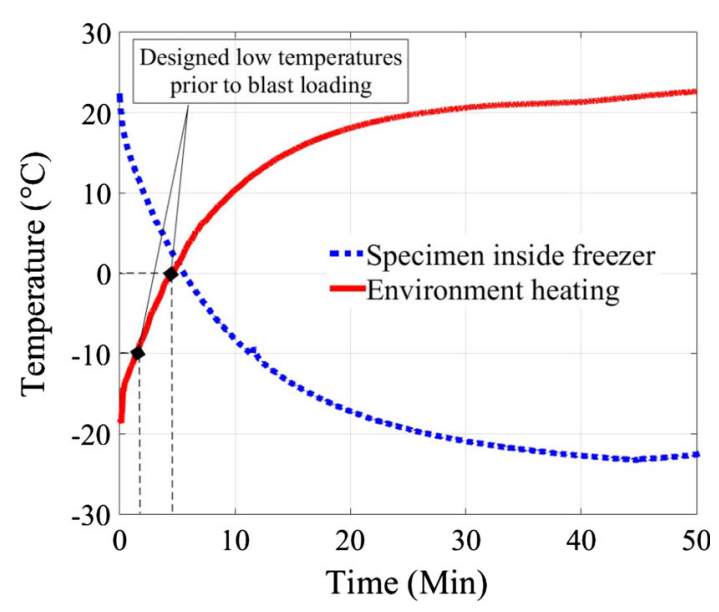

Fig. 6 Cooling calibration plot for -10 and $0{ }^{\circ} \mathrm{C}$ experiments
Fig. 5 Heating setup for shock loading experiments

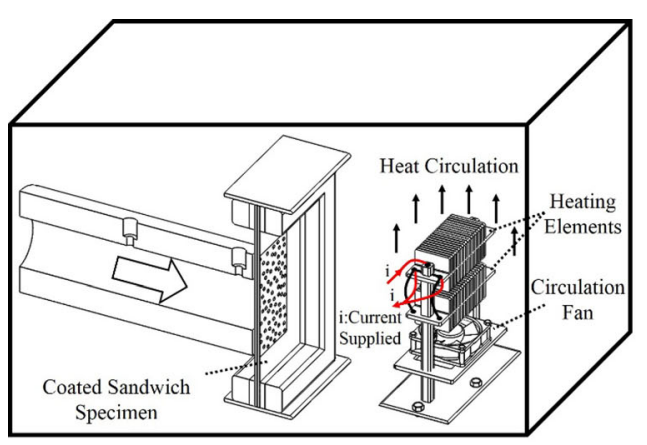

(a) Experimental setup showing the thermally insulated heating enclosure

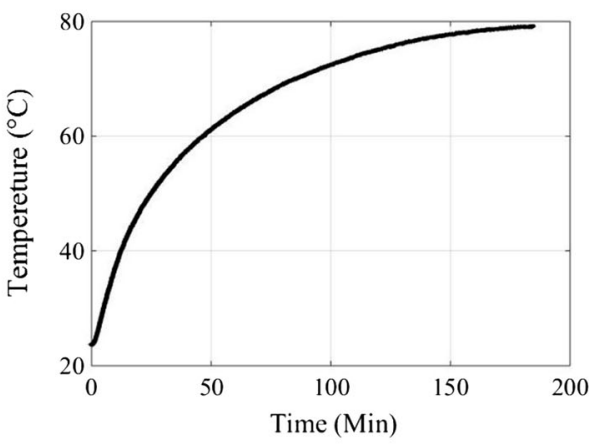

(b) Steady state heating calibration plot for $80^{\circ} \mathrm{C}$ 
Fig. 7 Experimental highspeed photography setup showing the back-view 3D-DIC system

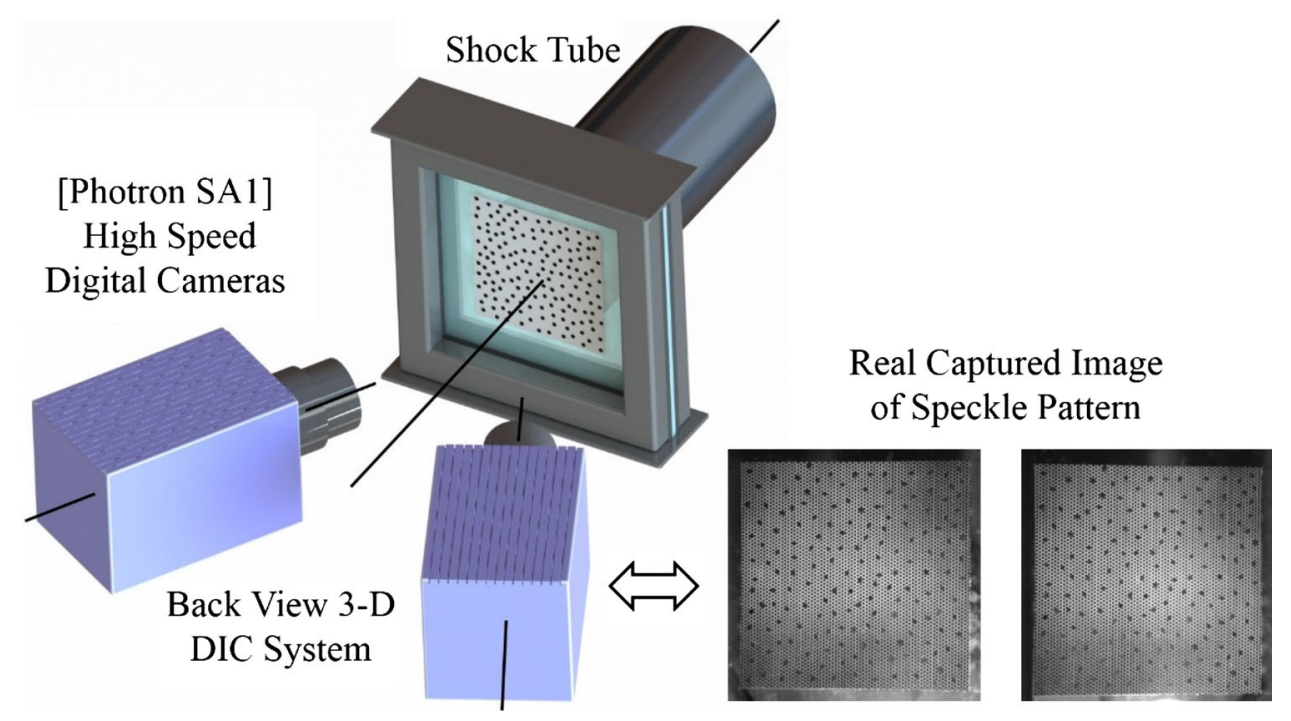

(DIC) technique used images with a speckle pattern from the high speed cameras to obtain the full field deformation, velocities, and strains of each sandwich specimen during loading. Flat paint was used to create a random, high contrast speckle pattern on the surface of each sandwich specimen in order for the DIC technique to work. Figure 7 shows a real captured image of the speckle pattern. The DIC analysis was then performed using VIC-3D software from Correlated Solutions.

\section{Tensile Testing of Coating Material Under Different Temperatures}

In order to characterize and correlate the response of the thermoplastic material used for coating the LSG panels, quasi-static tensile tests on XO $\mathrm{ARMOR}^{\circledR}$ protective films were performed at the same desired temperature environments as the shock loading experiments. To achieve the desired range of testing temperatures around the film specimens prior to and during testing, an environmental chamber (330 mm long $\times 381 \mathrm{~mm}$ wide, $762 \mathrm{~mm}$ high) made of thermal insulation foam was designed and fitted to the tensile testing machine. A schematic of the experimental setup is shown in Fig. 8. For testing the protective film under high temperatures $\left(50,80,110^{\circ} \mathrm{C}\right)$, a heating element with variable DC power supply (0-60 V) was utilized to control the amount of heat generated. A circulation fan was used to ensure proper air-circulation. By controlling the voltage supplied to the chamber, different steady state high temperatures were achieved. Film specimens were heated as shown in Fig. 8a for approximately 40-50 min until the desired temperature was reached. For low temperature tensile testing, dry ice $\left(\mathrm{CO}_{2}\right)$ was placed in small containers to create a large surface area as well as achieve high sublimation rates inside the chamber. Different steady state low temperatures were achieved by controlling the amount of dry ice and air flow rate of circulation fan. Film specimens were cooled down as shown in Fig. 8c for approximately 12 and $20 \mathrm{~min}$ until the desired temperature was reached. In the present study, the temperature was measured (using a K-type thermocouple) directly on samples until their temperature stabilized at the desired level. Typical temperature-time plots for tensile specimens at high and low temperatures are shown in Fig. 8b, d respectively.

The film cutting procedures were followed by ASTM (D-6287) standard [27] using a dual blade shear cutter technique. The sample preparation and cutting direction have a direct influence on the test results "since it alters the material properties". In general, the molecular orientation in the transverse (perpendicular) cutting direction is relatively weak and requires less energy to fracture as compared to the sheet rolling direction which is stronger. Therefore, in order to account for a worst-case failure scenario, tests were carried out for samples cut perpendicular to the sheet rolling direction. Uniform strips measuring $0.279 \mathrm{~mm}$ thick, $215.9 \mathrm{~mm}$ long, and with a nominal width of $20.0 \mathrm{~mm}$ were used. It was ensured that these strips had straight, clean, parallel edges with no visible imperfections. The film materials underwent tensile testing in accordance with the ASTM (D-882) standard [28]. Prior to each test, film specimens with gage length of $107.7 \mathrm{~mm}$ were fitted between wedge grips of the Instron 3366 testing machine equipped with a $10 \mathrm{KN}$ load cell and data acquisition software, then pulled until complete failure. The tensile tests were conducted with a loading speed of $50 \mathrm{~mm} / \mathrm{min}$ in order to accomplish a constant sample deformation (strain) rate of $0.0083(\varepsilon / \mathrm{s})$. For each 


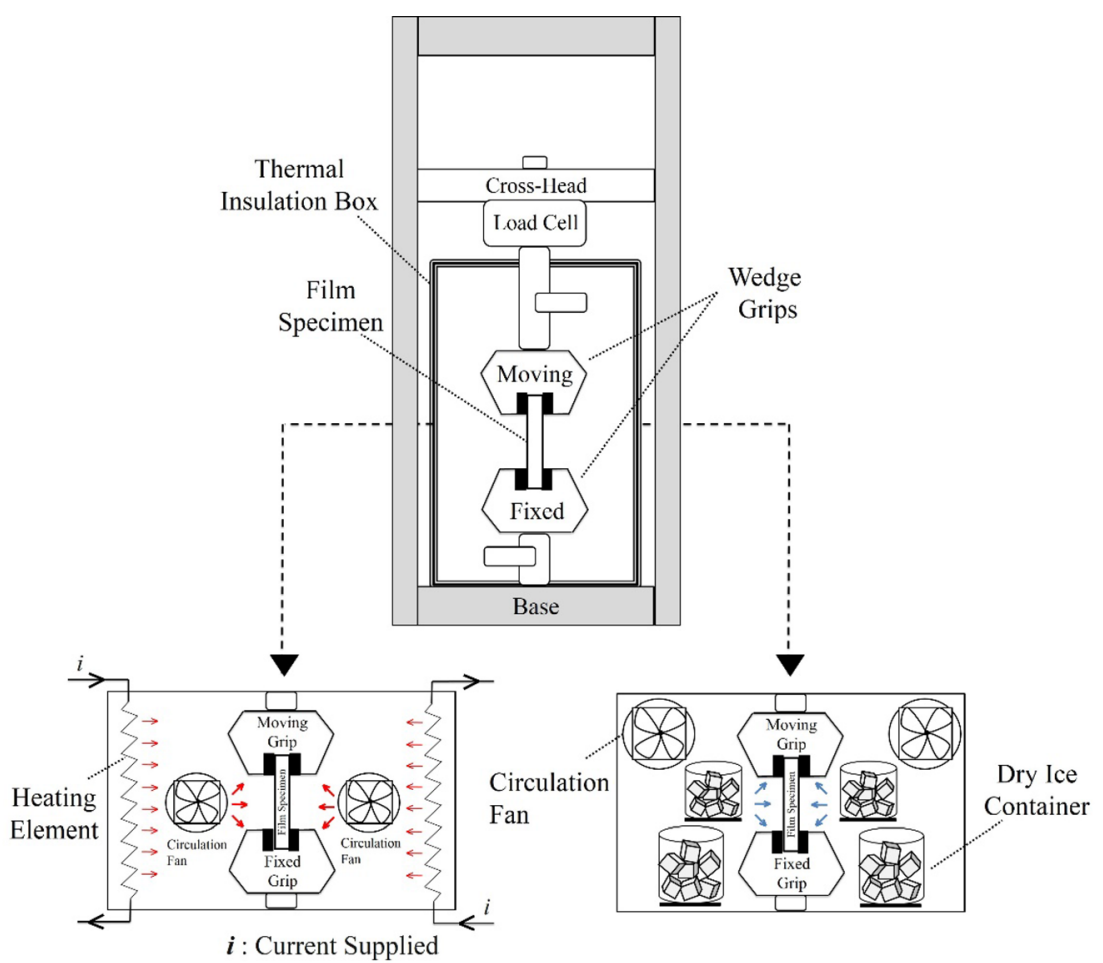

(a) High Temperature Setup

(c) Low Temperature Setup

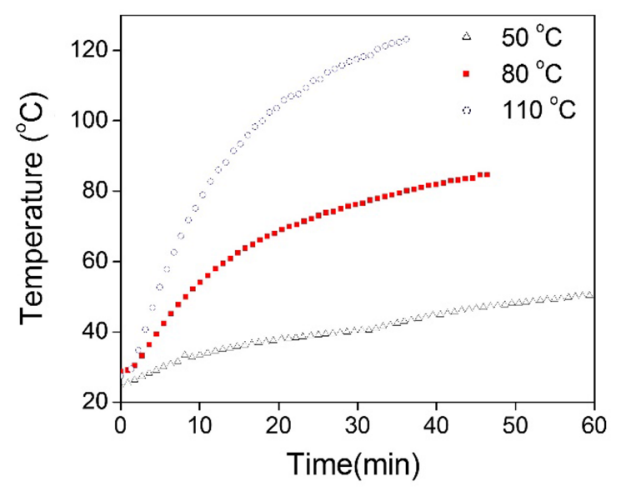

(b) High Temperature Calibration

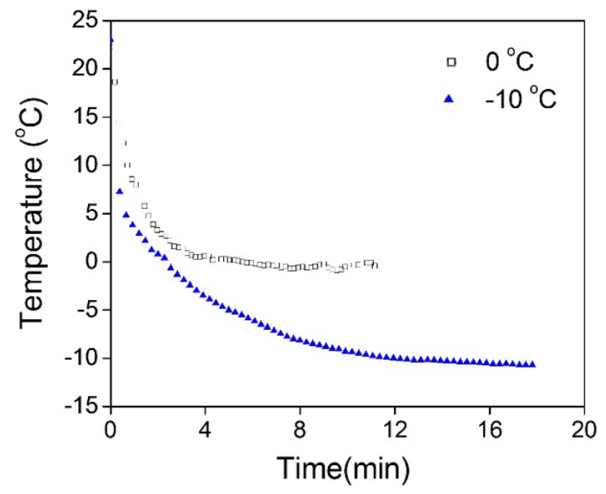

(d) Low Temperature Calibration

Fig. 8 Modified Instron machine setup for tensile experiments at high and low temperature environment

temperature, a minimum of five repetitions were performed to verify consistency in the test results.

\section{Experimental Results and Discussion}

\section{XO-ARMOR Response}

The effect of temperature on the stress-strain curve for the film coating is shown in Fig. 9. This figure denotes that the XO-ARMOR materials showed both possibilities of ductile and brittle failure as in most thermoplastic polymers. The temperature increase leads to a decrease in elastic modulus, reduction in tensile strength, and an increase in ductility. Conversely, brittle fracture was favored at lower temperatures.

At room temperature, the coating material showed a $95 \mathrm{MPa}$ yield stress and a Young's modulus of $3.5 \pm 0.01$ $\mathrm{GPa}$. As the temperature decreased to $-10{ }^{\circ} \mathrm{C}$, the coating film showed maximum yield stress of $128 \mathrm{MPa}$ and exhibited maximum Young's modulus of $4.2 \pm 0.01 \mathrm{GPa}$. Thermal softening occurs as the temperature increased to $110{ }^{\circ} \mathrm{C}$ in which the yield stress dropped to about $26 \mathrm{MPa}$ and the elastic modulus achieved a minimum value of $1.3 \pm 0.01 \mathrm{GPa}$. The yield strength at $-10{ }^{\circ} \mathrm{C}$ was about $35 \%$ higher than that at a temperature of $25{ }^{\circ} \mathrm{C}$, while it 


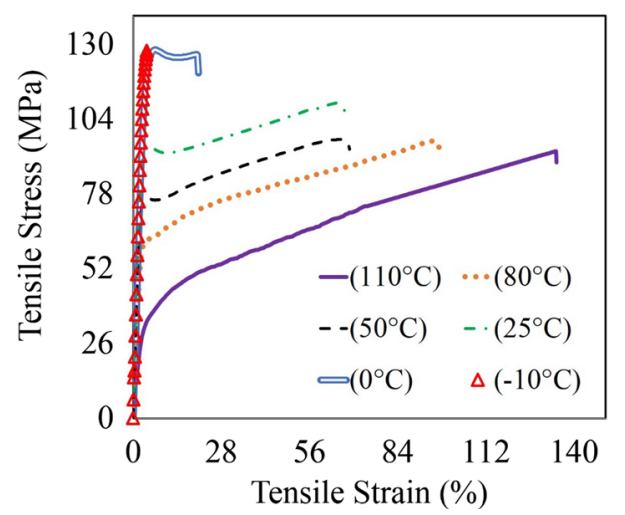

Fig. 9 Tensile stress-strain curves of XO ARMOR ${ }^{\circledR}$ protective film under quasi-static loading at different temperatures

was lower by approximately $73 \%$ at $110{ }^{\circ} \mathrm{C}$. The Young's modulus at low temperature $\left(-10{ }^{\circ} \mathrm{C}\right)$ was about 3.2 times higher than that at high temperature $\left(110^{\circ} \mathrm{C}\right)$.

The qualitative nature of the failure strain at different temperatures is shown in Fig. 10. The elongation at break increased with increasing temperature from -10 to $110{ }^{\circ} \mathrm{C}$. The coating material showed a failure strain of $53 \%$ at room temperature. A minimum failure strain of $5 \%$ was exhibited by the coating material at a temperature of $-10{ }^{\circ} \mathrm{C}$ whereas the material showed a maximum failure strain of $135 \%$ at $110{ }^{\circ} \mathrm{C}$. The average values of tensile energy to break (TEB) depending on the temperature are also shown by Fig. 10. The TEB is defined in the present study as the total energy absorbed per unit volume of the film specimen up to the point of rupture and is calculated by integrating the area under the stress-strain curves. The maximum TEB of $81.2 \mathrm{MJ} / \mathrm{m}^{3}$ was observed for $110{ }^{\circ} \mathrm{C}$. The coating material at $-10,0,25,50$ and $80{ }^{\circ} \mathrm{C}$ showed maximum TEB of 3.1, $20.4,50.5,62.2$, and $74.6 \mathrm{MJ} / \mathrm{m}^{3}$, respectively. The magnitude of tensile energy to failure at $110{ }^{\circ} \mathrm{C}$ was 78 times

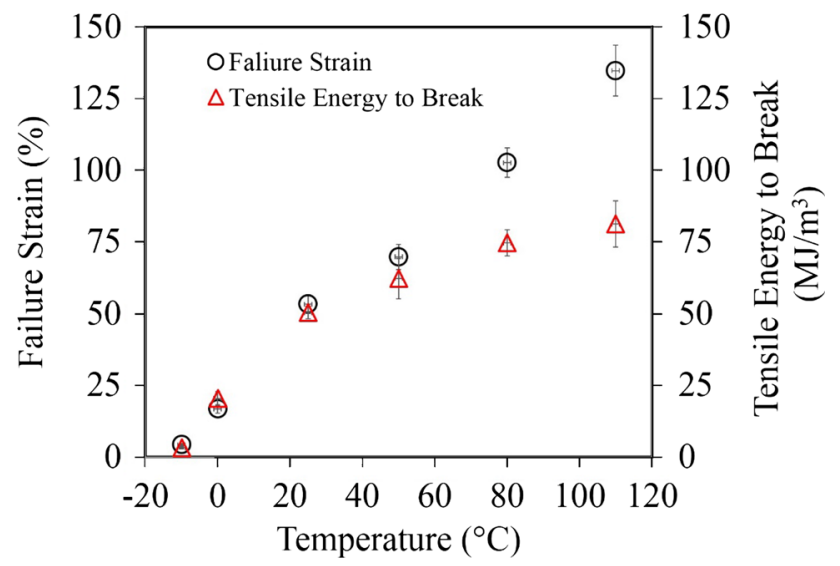

Fig. 10 Failure strain and energy absorption of the coating material as a function of temperature higher than that at $-10{ }^{\circ} \mathrm{C}$. The mechanical behavior of $\mathrm{XO}$ ARMOR materials signifies their excellent ability to absorb more energy under high temperatures. The glass transition temperature of the film coating is between -10 and $0{ }^{\circ} \mathrm{C}$ below which it exhibits brittle failure. The trend changes in yield stress and elongation as a function of temperature observed are expected to be qualitatively similar even at higher strain-rates. Brown et al. [29] have shown that the trend changes in yield stress as a function of temperature and strain-rate in polymers can be expressed by linear and logarithmic fits respectively. Furmanski et al. [30] showed that the quasi-static data at depressed temperatures can be used to predict high strain rate response after correcting for adiabatic heating.

\section{Room Temperature Response}

In the current work, the applied shock load was experienced by the sandwich specimen during fluid-structureinteraction (FSI) time. This period of time is considered the early stage of blast loading. Figure 11 shows that the shock wave impinged on the sandwich specimen at $t=0 \mu$ s. Then circular deflection contours on the back face begins to appear at $\mathrm{t}=50 \mu \mathrm{s}$ showing that the stress wave has propagated through the front face of the sandwich specimen. After that, these deflection contours evolved with time. During (FSI) time, the boundary conditions had no influence on the structural dynamic response of the sandwich specimen. In which, there was not any glass fractures (cracks) observed in any of the glass plies of the sandwich specimen for the first $200 \mu$ s of the blast event and a relatively minimal out-of-plane deflection of approximately $1.9 \mathrm{~mm}$ with in-plane strain of $0.4 \%$, as shown in Fig. 11a, b respectively. After the (FSI) time, the whole sandwich specimen started experiencing significant outward deflection and the deformation from here on was affected by the boundary conditions and the dynamic material properties of both the interlayer and film coating.

The real time images (Fig. 12) showed that the sandwich specimen at room temperature underwent internal damage (glass plies started to break) at $\mathrm{t}=250 \mu \mathrm{s}$ and damage (cracks) that begin close to the boundaries. The shear force at the boundary causes the glass to crack, similar to observations reported by Zhang et al. [16]. At $\mathrm{t}=300 \mu \mathrm{s}$, circular crack pattern formed from the central area of the blast loading. After glass has fragmented only the PVB and coating materials resist the blast loading and thus the structural stiffness reduces. The glass plies continue breaking into smaller fragments up to the point of maximum deflection at $\mathrm{t}=2000 \mu \mathrm{s}$. This fragmentation process of glass up to the point of peak deformation is a unique energy dissipation mechanism offered by this construction of sandwich panel. 
Fig. 11 Back-face a deflection and $\mathbf{b}$ strain contours of sandwich specimen during fluid-structure interaction time for room temperature experiment

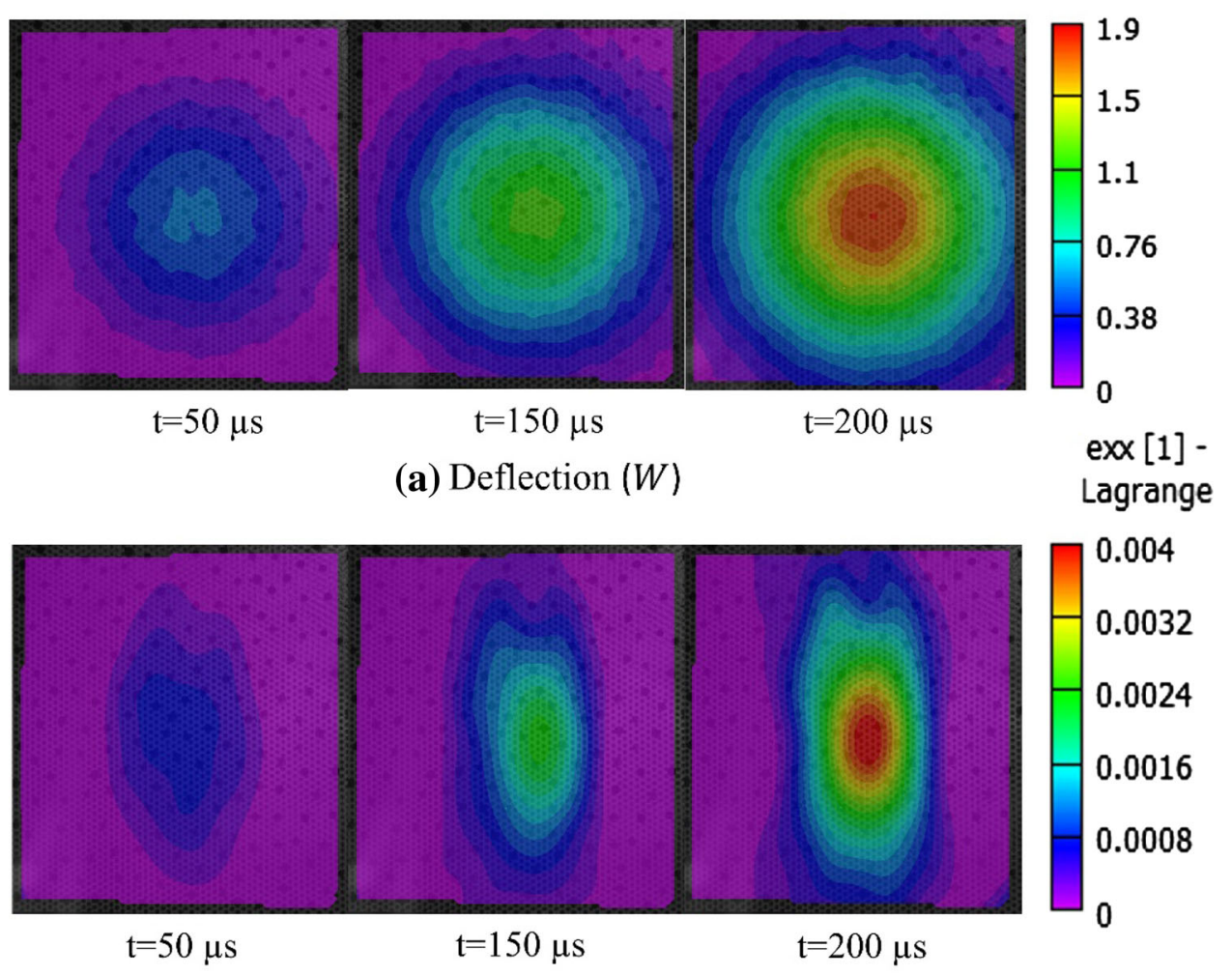

(b) In plane strain $\left(\varepsilon_{x x}\right)$

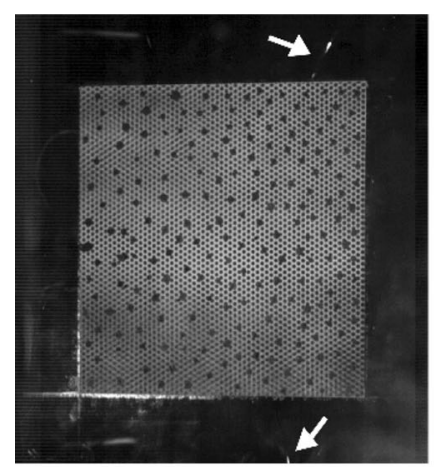

$\mathrm{t}=250 \mu \mathrm{s}$

Crack initiation at the boundaries

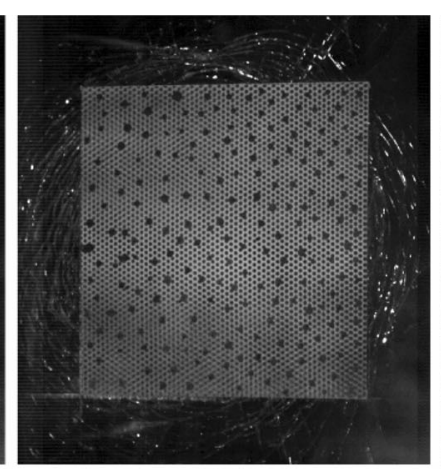

$\mathrm{t}=300 \mu \mathrm{s}$

Circular crack pattern initiating from center

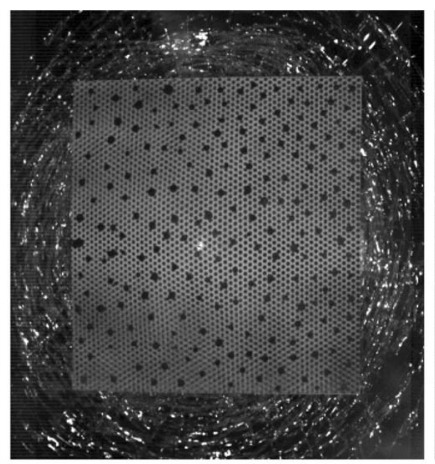

$\mathrm{t}=700 \mu \mathrm{s}$

Continuation of glass breaking to boundaries

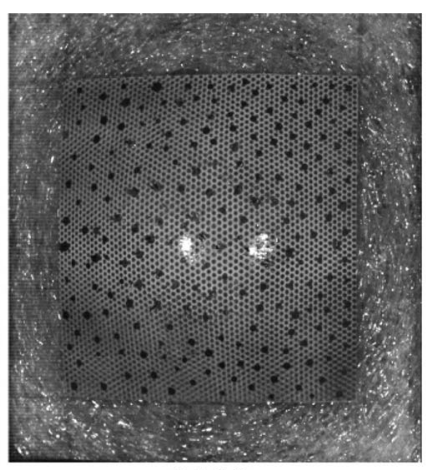

$\mathrm{t}=2000 \mu \mathrm{s}$

Small glass fragmentations at point of maximum deflection

Fig. 12 Real time images of glass breaking plies of the sandwich specimen at $25{ }^{\circ} \mathrm{C}$

The deformation mechanisms of the sandwich specimen under blast loading are described as follows. The panel started with elastic behavior until the first glass ply was broken, while the other layer of glass was still intact where the PVB interlayer and film coating were both undamaged. After that the second glass ply failed and both the interlayer and film coating materials behaved elastically. Then, as the entire panel remained under loading, both the interlayer and film coating behaved plastically. The glass fragmentations were kept together by film coating and the PVB materials for further deformations until failure occurred. Both the interlayer and film coating fail by reaching their failure strain or by cutting from the splinters. Larcher et al. [11] reported similar failure of laminated glass sheets where the PVB interlayer alone was resisting the air blast waves while keeping the splinters together. 
For better understanding of the film coating effects on blast mitigation properties of LSG panels close to room temperature, full field of out-of-plane deflection and inplane strain history over an extended time $(\mathrm{t}=4000 \mu \mathrm{s})$ were investigated as shown in Fig. 13. At $t=700 \mu \mathrm{s}$, the sandwich specimen deflected $15.5 \mathrm{~mm}$ with $6 \%$ strain. At $(\mathrm{t}=2000 \mu \mathrm{s})$, the specimen reached its maximum deflection of $35.3 \mathrm{~mm}$ with $12.8 \%$ strain and then began to rebound. At $(\mathrm{t}=4000 \mu \mathrm{s})$, the sandwich specimen settled to a final out-of-plane deflection of $24.7 \mathrm{~mm}$ and in-plane strain of $8.4 \%$. It is clear that the deflection and strain were concentric about the mid-point and that the central portion of the film coating is subjected to large tensile strains. The protective film was able to keep the shattered glass pieces from flying away and controlled the damage propagation.

\section{Effect of Temperature on Sandwich Specimen Response}

The temperature effect on stress wave propagation through the sandwich specimen during FSI time (up to $\mathrm{t}=200 \mu \mathrm{s}$ ) was investigated in the present study. The stress wave propagates with lower wave speeds at higher temperature environments as compared to room and low experiments shown in Fig. 14a-c respectively. In the latter cases, the stress waves take longer to propagate and stabilize. Similar phenomena of FSI time for marine foam core sandwich composites were reported in previous studies by Gupta and Shukla [31].

The data at the center point of the back face for each experiment was evaluated and plotted using the point-inspection tool from the digital image correlation software. The temperature effect on the mean back-face deflection history is shown in Fig. 15. As discussed earlier in
Fig. 13a, the room temperature specimen showed a maximum deflection of $35.3 \mathrm{~mm}$ at $\mathrm{t}=2000 \mu$ s and then began to rebound. For the $0{ }^{\circ} \mathrm{C}$ experiment, the composite structure showed a maximum back-face deflection of $29.7 \mathrm{~mm}$ at $\mathrm{t}=1800 \mu \mathrm{s}$ and began to rebound. As the temperature decreased to $-10{ }^{\circ} \mathrm{C}$, the sandwich panel reached deflection of $14.2 \mathrm{~mm}$ and then began to fail at $\mathrm{t}=700 \mu \mathrm{s}$. It should be noticed that the specimen at lower temperatures responded quicker due to its higher stiffness and began to rebound ahead of time, $200 \mu$ s (for $0{ }^{\circ} \mathrm{C}$ case), as compared to room temperature. At $\mathrm{t}=4000 \mu \mathrm{s}$, the sandwich specimen at $0{ }^{\circ} \mathrm{C}$ experiment settled with $12 \%$ less out-of-plane deflection as compared to the $25^{\circ} \mathrm{C}$ experiment.

Under the same air blast load, the panel at higher temperatures deformed faster and with larger maximum deflections. This is because PVB interlayer and coating materials were both quite flexible (more rubbery) and had significant contribution to the ductility of the composite structure. In comparison to the room temperature experiment, the sandwich specimen at 50 and $80{ }^{\circ} \mathrm{C}$ deformed for additional 600 and $1000 \mu$ s respectively before reaching their maximum deflection. For high temperatures of 50 and $80{ }^{\circ} \mathrm{C}$, the sandwich specimens deflected in a similar manner prior to reaching their maximum deflection of 50.7 and $61.0 \mathrm{~mm}$ at $\mathrm{t}=2600 \mu$ s and $3000 \mu$ s respectively and then began to rebound. However, as the temperature increased to $110^{\circ} \mathrm{C}$, the specimen reached deflection of $42.3 \mathrm{~mm}$ and began to fail at $\mathrm{t}=1000 \mu \mathrm{s}$. At $\mathrm{t}=4000 \mu \mathrm{s}$, experiments of 50 and $80{ }^{\circ} \mathrm{C}$ respectively showed 69 and $135 \%$ more out-of-plane deflection on the back face of the sandwich specimen as compared to the $25^{\circ} \mathrm{C}$ experiment.

Figure 16 shows the out-of-plane particle velocity (dW/ dt) on the back face of the sandwich panel at different
Fig. 13 Typical full field DIC results of the sandwich specimen back face from a blast experiment at $25^{\circ} \mathrm{C}$ for both a out-of-plane deflection with a scale of $0 \mathrm{~mm}$ (purple) to $35 \mathrm{~mm}$ (red) and $\mathbf{b}$ in-plane strain with a scale of 0 (purple) to 0.13 (red) (Color figure online)

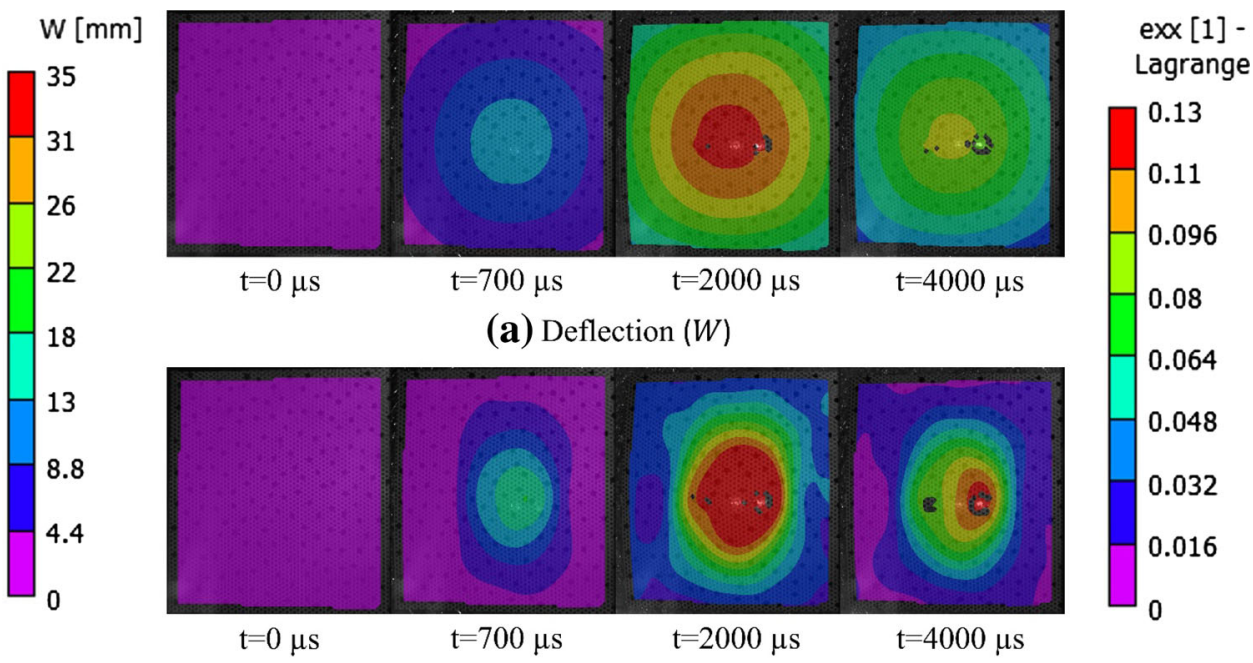

(b) In plane strain $\left(\varepsilon_{x x}\right)$ 
Fig. 14 Circular deflection contours with a scale of $0 \mathrm{~mm}$ (purple) to $1.9 \mathrm{~mm}$ (red) of the specimen back face during FSI time (Color figure online)

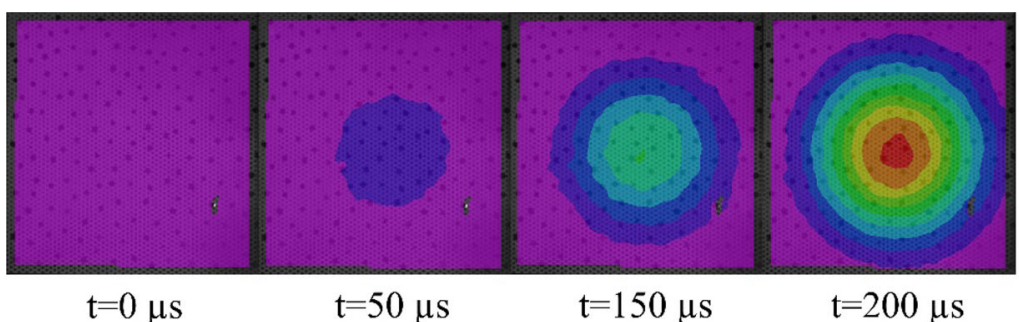

(a) High Temperature $\left(110^{\circ} \mathrm{C}\right)$
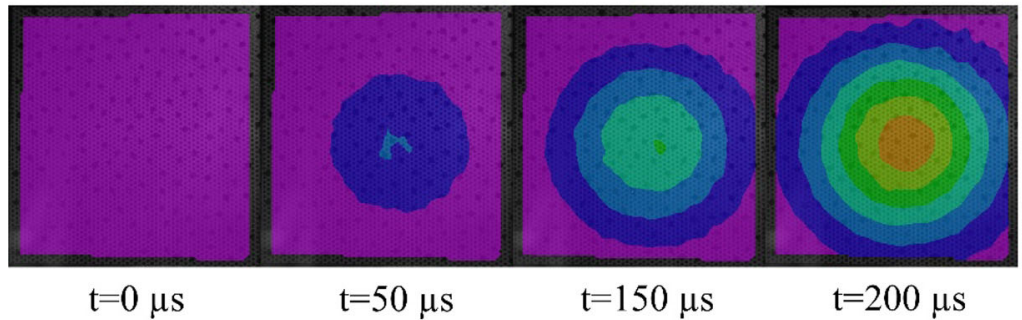

$\mathrm{t}=50 \mu \mathrm{s}$

$\mathrm{t}=150 \mu \mathrm{s}$

$\mathrm{t}=200 \mu \mathrm{s}$

(b) Room Temperature $\left(25^{\circ} \mathrm{C}\right)$

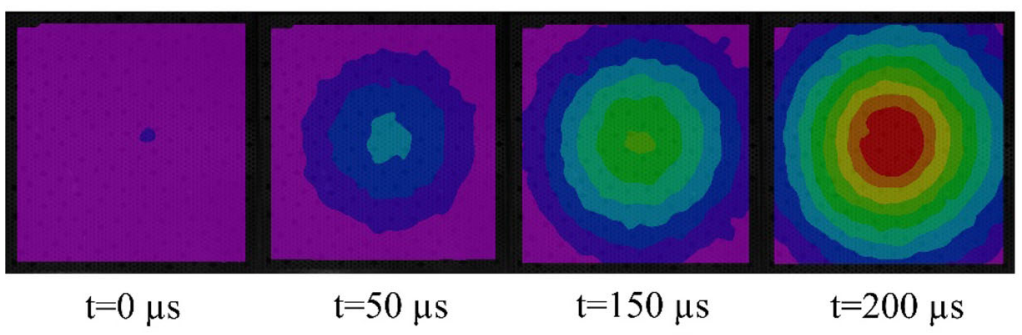

(c) Low Temperature $\left(-10^{\circ} \mathrm{C}\right)$
$\mathrm{W}[\mathrm{mm}]$

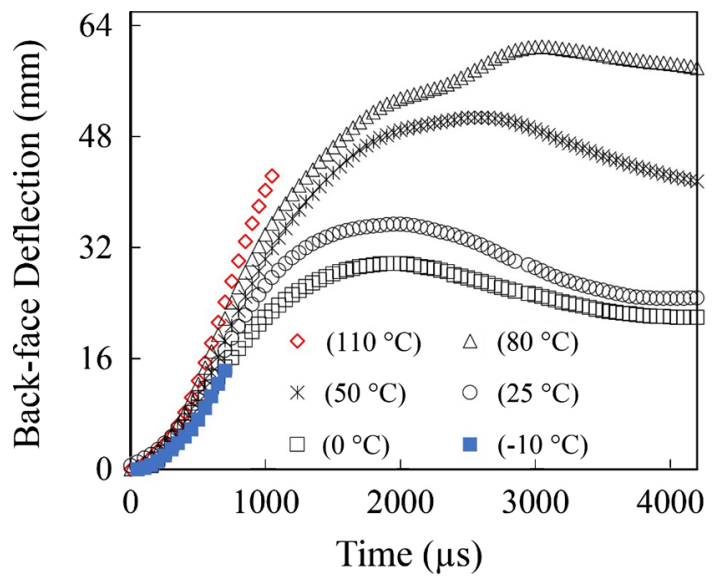

Fig. 15 Mean center-point back-face deflections histories of specimens at different environment temperatures using DIC analysis

temperatures. A steep increase in velocity is seen at around $\mathrm{t}=300 \mu \mathrm{s}$. This time corresponds to the occurrence of glass fragmentation which reduces the stiffness and causes the outward acceleration of the composite. For 0 to $80^{\circ} \mathrm{C}$, the sandwich specimens reached their maximum velocities between $\mathrm{t}=700$ and $800 \mu$ s. The room temperature

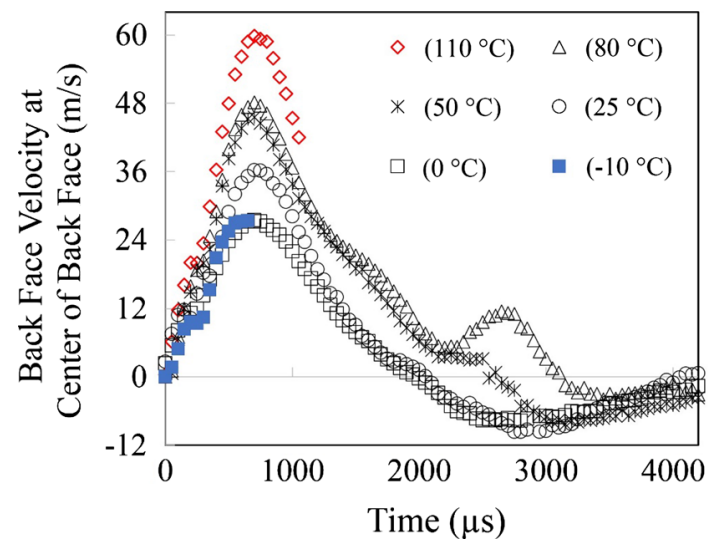

Fig. 16 Back face out-of-plane velocity profiles of specimen at different environment temperatures calculated from DIC

specimen had a maximum velocity of $36.0 \mathrm{~m} / \mathrm{s}$ at $\mathrm{t}=750 \mu \mathrm{s}$ and it started to decelerate after that. This means the velocity continues to be reduced to approximately $0 \mathrm{~m} / \mathrm{s}$ as the specimen reached its maximum deflection (at $\mathrm{t}=2000 \mu \mathrm{s}$ ) and began to rebound. When the specimen temperature dropped to $0{ }^{\circ} \mathrm{C}$, the maximum velocity is $27.4 \mathrm{~m} / \mathrm{s}$, and this lower velocity can be 
Fig. 17 Full field in-plane strain $\left(\varepsilon_{\mathrm{xx}}\right)$ at maximum deflection or at failure of sandwich specimen at different environment temperatures

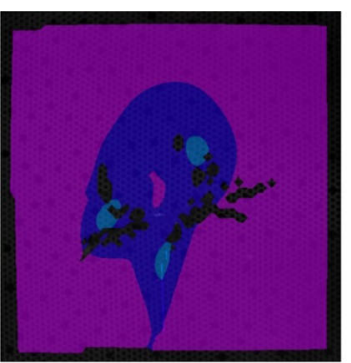

(a) $-10^{\circ} \mathrm{C}$

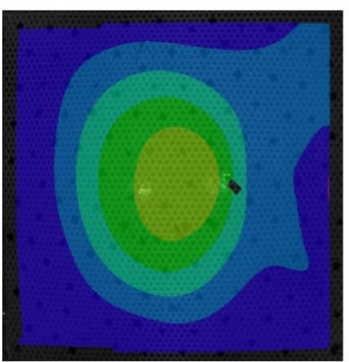

(d) $50^{\circ} \mathrm{C}$

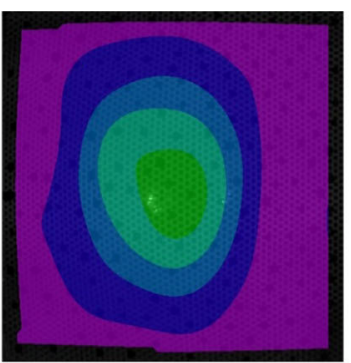

(b) $0{ }^{\circ} \mathrm{C}$

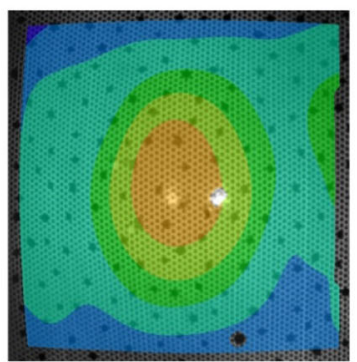

(e) $80^{\circ} \mathrm{C}$

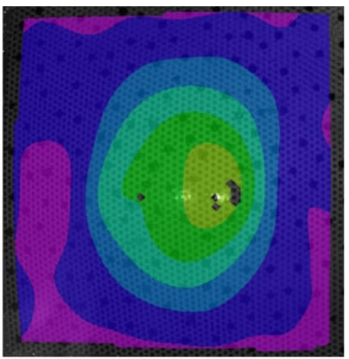

(c) $25^{\circ} \mathrm{C}$

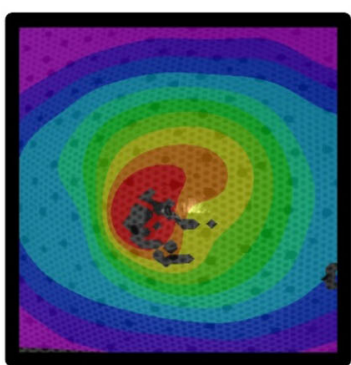

(f) $110^{\circ} \mathrm{C}$ $\operatorname{exx}[1]-$ Lagrange

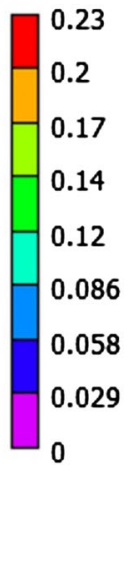

0.2

0.17

0.14

0.12

0.086

0.058

0.029
Fig. 18 Real time images of sandwich specimen showing the failure process at low $\left(-10{ }^{\circ} \mathrm{C}\right)$ and high $\left(110^{\circ} \mathrm{C}\right)$ temperature
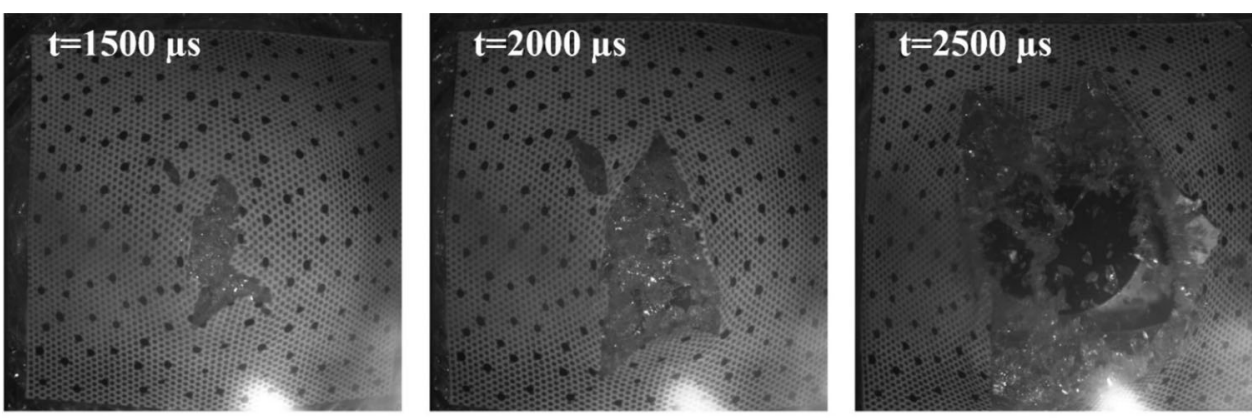

(a) High Temperature $\left(110^{\circ} \mathrm{C}\right)$
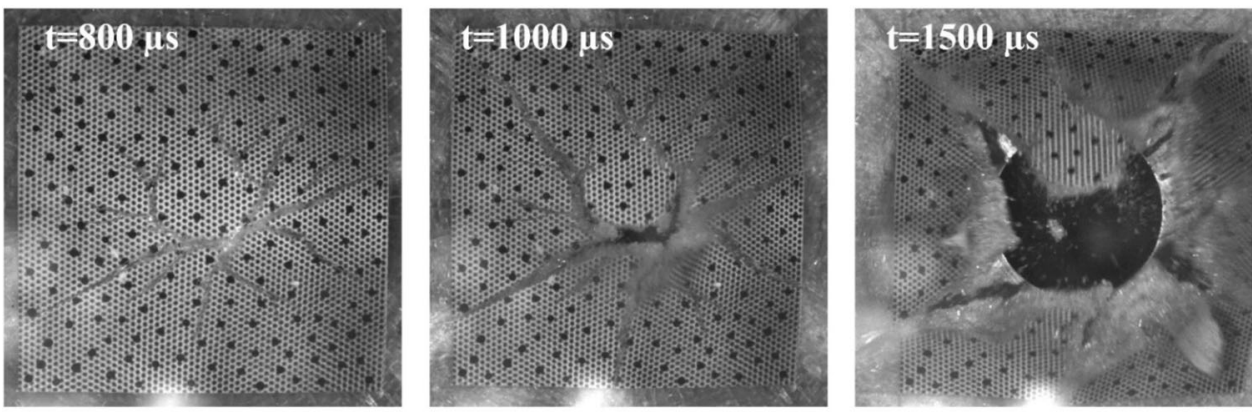

(b) Low Temperature $\left(-10{ }^{\circ} \mathrm{C}\right)$

attributed to higher stiffness of coating and PVB materials. Prior to failure at $-10{ }^{\circ} \mathrm{C}$, the sandwich specimen had a velocity of $26.5 \mathrm{~m} / \mathrm{s}$. Under high temperature experiments at 50 and $80{ }^{\circ} \mathrm{C}$, the sandwich specimen reached higher peak velocities of 45.5 and $48.2 \mathrm{~m} / \mathrm{s}$ respectively due to a decrease in coating stiffness. At $110{ }^{\circ} \mathrm{C}$, the sandwich specimen reached peak velocity of $60.0 \mathrm{~m} / \mathrm{s}$ and the film coating was intact at this point. The film coating was able to decelerate the center of the back face velocity from 60.0 to $45.4 \mathrm{~m} / \mathrm{s}$ as shown in Fig. 16. In this deceleration process the coating material was stretched (strained) further and it ruptured. Even though the coating material failed, the load bearing capacity of the film and its contribution in reducing the speed of the glass fragments are notable. 


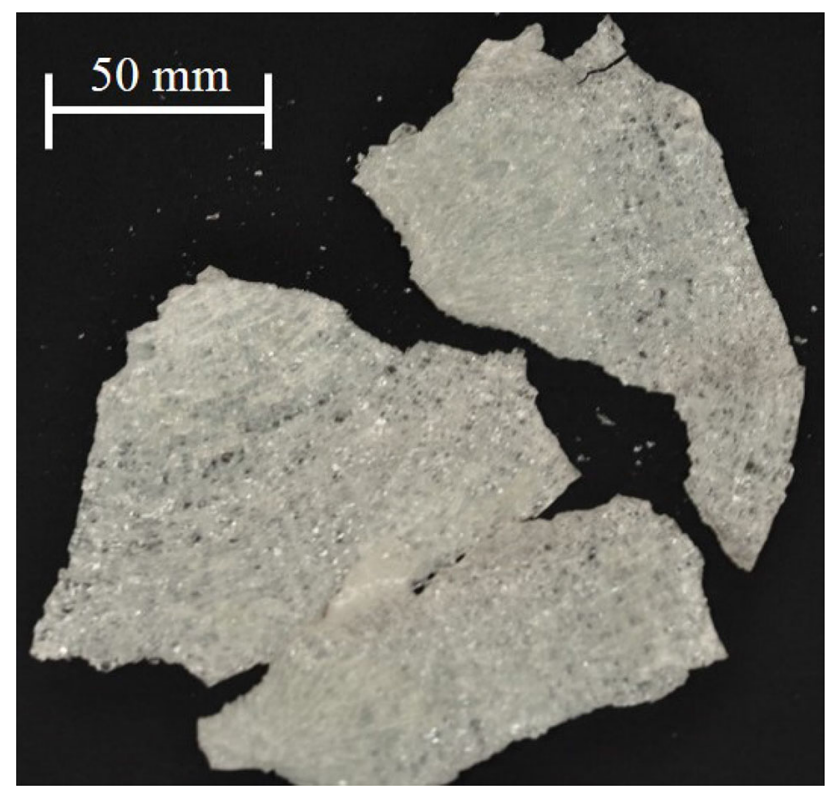

Fig. 19 PVB interlayer at $-10{ }^{\circ} \mathrm{C}$ holding glass fragments

The full field of in-plane strains $\left(\varepsilon_{\mathrm{xx}}\right)$ on the back-face of the sandwich specimen at maximum deflection or at failure for temperatures ranging from -10 to $110{ }^{\circ} \mathrm{C}$ are shown in Fig. 17. For $-10{ }^{\circ} \mathrm{C}$ (Fig. 17a), the sandwich specimen reached $6 \%$ in-plane strain and then failed. This is in-line with the results of tensile experiments on the coated film which showed brittle failure at $-10{ }^{\circ} \mathrm{C}$ when strained to $5 \%$. Figure 17 shows that the in-plane strain of the sandwich specimen increases with increasing temperature. The composite panel showed great endurance during the blast loading for temperatures ranging from 0 to $80{ }^{\circ} \mathrm{C}$ (Fig. 17b-e). In-plane strains of 9, 12.8, 16, and $19.3 \%$ were experienced by the coating at temperatures of 0,25 , 50 , and $80{ }^{\circ} \mathrm{C}$ respectively. At $110{ }^{\circ} \mathrm{C}$ (Fig. 17f), the panel showed $23 \%$ in-plane strain at the time of failure. This strain is much lower than the failure strain observed in $110{ }^{\circ} \mathrm{C}$ tensile experiment on coating film. Thus it can be inferred that this failure in the coating material was due to the tearing of the film by the glass fragments, which is due to the failure of PVB section at higher temperatures.

The real time images captured during the experiment were studied to further investigate the failure process at 110 and $-10{ }^{\circ} \mathrm{C}$. From the images (Fig. 18a) we can observe that many small glass fragments were flying out of the sandwich specimen, showing that the PVB interlayer was not able to contain them (PVB material loses strength at high temperatures). The de-bonding of glass fragments from PVB interlayer might have facilitated the rupture of the coating film by the glass fragments. However, as seen in (Fig. 18b) the PVB interlayer at $-10{ }^{\circ} \mathrm{C}$ was able to hold a substantial amount of the small glass fragments together even after catastrophic failure of the coating material. Figure 19 shows how these glass fragments were contained by the PVB interlayer. This signifies the critical role of PVB interlayer in the performance of the sandwiched structure.

\section{Conclusion}

This study focused on the dynamic response of laminated glass composite, which is coated with XO-Film, under combined shock loading and extreme temperatures. The major findings of this study are as follows:

- There was substantial glass fragmentation at all temperatures. However, the coating material and PVB interlayer enabled structural integrity, controlled the damage propagation, and prevented glass pieces from flying away at temperatures ranging from $\sim 0$ to $\sim 80^{\circ} \mathrm{C}$. In which case both interlayer and coating materials survived the shock loading with no catastrophic failure.

- PVB interlayer at $-10{ }^{\circ} \mathrm{C}$ was able to hold a substantial amount of the small glass fragments together even after catastrophic failure of the coating material.

- The failure at $110{ }^{\circ} \mathrm{C}$ is likely due tearing of the coating by the glass fragments.

- Due to the temperature-dependent material properties of the protective film coating and PVB interlayer, the sandwich specimen showed an increasing trend in back-face deflection and in-plane strain with increasing temperature.

- The fragmentation process of glass continues to the point of peak deformation. This is a unique energy dissipation mechanism offered by this construction of sandwich panel.

- For good performance of this type of sandwich structure geometry, both the interlayer and the coating film should have good ductility and strength at the target temperatures.

Acknowledgments The authors acknowledge XO Armor for providing the XO-Film ${ }^{\circledR}$ and Chris Salazar for carefully reading and editing the manuscript.

\section{References}

1. Norville HS, GRTL (1987) Misty picture data: window glass experiment, final data report. Glass Research and Testing Laboratory, Texas Tech University, Lubbock, Lubbock

2. Norville HS, Harvill N, Conrath EJ et al (1999) Glass-related injuries in Oklahoma City bombing. J Perform Constr Facil 13:50-56 
3. Smith D (2001) Glazing for injury alleviation under blast loading, United Kingdom practice. In: Glass processing days conference proceedings, pp 335-340

4. Stephens RAC (2008) Determination of the resistance of laminated glass subjected to blast loading using high speed video, M.Sc. thesis, Cranfield University

5. Kumar Puneet, Shukla Arun (2011) Dynamic response of glass panels subjected to shock loading. J Non-Cryst Solids 357:3917-3923

6. Shetty MS, Wei J, Dharani LR, Stutts DS (2013) Analysis of damage in laminated architectural glazing subjected to wind loading and windborne debris impact. Buildings 3:422-441

7. Zhang X, Hao H, Wang Z (2015) Experimental study of laminated glass window responses under impulsive and blast loading. Int J Impact Eng 78:1-19

8. UFC 4-010-01 (2003) Minimum antiterrorism standards for buildings. Unified Facilities Criteria, Department of Defense, Washington DC

9. ASTM F2248 (2009) Standard practice for specifying an equivalent 3-second duration design loading for blast resistant glazing fabricated with laminated glass. ASTM, West Conshohocken

10. Wei J, Shetty MS, Dharani LR (2006) Failure analysis of architectural glazing subjected to blast loading. Eng Fail Anal 13:1029-1043

11. Larcher M, Solomos G, Casadei F, Gebbeken N (2012) Experimental and numerical investigations of laminated glass subjected to blast loading. Int J Impact Eng 39:42-50

12. Hooper P, Arora H, Dear JP (2010) Blast and impact resistance of laminated glass structures. In: Proceedings of the IMPLAST 2010 conference, Providence

13. Hooper PA, Sukhram RAM, Blackman BRK, Dear JP (2012) On the blast resistance of laminated glass. Int $\mathrm{J}$ Solids Struct 49:899-918

14. Wei J, Dharani LR (2006) Response of laminated architectural glazing subjected to blast loading. Int $\mathrm{J}$ Impact Eng 32:2032-2047

15. Zhang X, Hao H (2015) Experimental and numerical study of boundary and anchorage effect on laminated glass windows under blast loading. Eng Struct 90:96-116

16. Zhang X, Hao H, Ma G (2013) Parametric study of laminated glass window response to blast loads. Eng Struct 56:1707-1717

17. Hidallana-Gamage HD, Thambiratnam DP, Perera NJ (2014) Numerical modelling and analysis of the blast performance of laminated glass panels and the influence of material parameters. Eng Fail Anal 45:65-84
18. Peroni M, Solomos G, Pizzinato V, Larcher M (2011) Experimental investigation of high strain-rate behaviour of glass. Appl Mech Mater 82:63-68

19. Zhang X, Zou Y, Hao H et al (2012) Laboratory test on dynamic material properties of annealed float glass. Int J Prot Struct 3:407-430

20. Hooper PA, Blackman BRK, Dear JP (2011) The mechanical behaviour of poly (vinyl butyral) at different strain magnitudes and strain rates. J Mater Sci 47:3564-3576

21. Zhang X, Hao H, Shi Y, Cui J (2015) The mechanical properties of polyvinyl butyral (PVB) at high strain rates. Constr Build Mater 93:404-415

22. Wang E, Gardner N, Shukla A (2009) The blast resistance of sandwich composites with stepwise graded cores. Int J Solids Struct 46:3492-3502

23. Gardner N, Wang E, Kumar P, Shukla A (2011) Blast mitigation in a sandwich composite using graded core and polyurea interlayer. Exp Mech 52:119-133

24. Courant R, Friedrichs KO (1948) Supersonic flow and shock waves. Interscience Publishers, New York

25. Wang E, Shukla A (2010) Analytical and experimental evaluation of energies during shock wave loading. Int $\mathrm{J}$ Impact Eng 37:1188-1196

26. Wang E, Wright J, Shukla A (2011) Analytical and experimental study on the fluid structure interaction during air blast loading. J Appl Phys 110:114901-114912

27. ASTM D6287 (2009) Standard practice for cutting film and sheeting test specimens. ASTM International, West Conshohocken

28. ASTM D882 (2012) Standard test method for tensile properties of thin plastic sheeting. ASTM International, West Conshohocken

29. Brown EN, Willms RB, Iii GTG et al (2007) Influence of molecular conformation on the constitutive response of polyethylene: a comparison of HDPE, UHMWPE, and PEX. Exp Mech 47:381-393

30. Furmanski J, Cady CM, Brown EN (2013) Time-temperature equivalence and adiabatic heating at large strains in high density polyethylene and ultrahigh molecular weight polyethylene. Polymer 54:381-390

31. Gupta S, Shukla A (2012) Blast performance of marine foam core sandwich composites at extreme temperatures. Exp Mech 52(9):1521-1534 